\title{
DISASTER PLANNING AND EMERGENCY PREPAREDNESS
}

In case of disaster, the Institutional Officer, Chair of the IACUC, and Veterinarians will be notified of the situation.

Institutional Officer: Dr. Michael Sosulski 864-597-4020

Chair IACUC: Dr. Dave Pittman 864-266-6126

Veterinarians: Dr. Sonny King 864-590-2401 and Dr. Quint Carlisle 864-590-5226

Triage plan: The first official on the scene will identify the appropriate course of action based on the nature of the disaster situation. Critical or irreplaceable animals are identified on their animal ID tags and those animals will be given priority for care. Based on knowledge and familiarity with the animals the appropriate order of authority to make triage decisions would be institutional official deferring to chair of the IACUC deferring to the veterinarians.

If necessary, animals will be relocated to Smith Animal Hospital, located at 991 Asheville Hwy, Spartanburg, SC 29303 864-585-3401. If possible, pigeons will be relocated to the aviary at Dr. Alliston Reid's residence at 201 Briarcreek Dr., Spartanburg, SC 29301 864-574-5442.

If it is not possible to relocate the animals and they are incurring inhumane distress, the animals will be euthanized by the Principal Investigator responsible for the animals.

In case of HVAC or electrical failures, an alarm is triggered to alert Wofford Campus Safety. Wofford Campus Safety will then contact the Chair of the IACUC and the Physical Plant to inform them of the issue. Wofford College has staff on call 24 hrs to handle emergency loss of HVAC or electrical supply. Electrical generators and heaters are available for use if necessary.

All personnel receive training for action in the event of a disaster. The Disaster Plan is approved by Wofford College and a copy of this plan is provided to the IO, IACUC, and campus safety.

\section{Background}

Animal facilities may be subject to unexpected conditions that result in the catastrophic failure of critical systems or significant personnel absenteeism, or other unexpected events that severely compromise ongoing animal care and well-being (ILAR 2010). Facilities must therefore have a disaster plan. The plan should define the actions necessary to prevent animal pain, distress, and deaths due to loss of systems such as those that control ventilation, cooling, heating, or provision of potable water. If possible the plan should describe how the facility will preserve animals that are necessary for critical research activities or are irreplaceable. Knowledge of the geographic locale may provide guidance as to the probability of a particular type of disaster.

Disaster plans should be established in conjunction with the responsible investigator(s), taking into consideration both the priorities for triaging animal populations and the institutional needs and resources. Animals that cannot be relocated or protected from the consequences of the disaster must be humanely euthanized. The disaster plan should identify essential personnel who should be trained in advance in its implementation. Efforts should be taken to ensure personnel safety and provide access to essential personnel during or immediately after a disaster. Such plans should be approved by the institution and be part of the overall institutional disaster response plan that is coordinated by the $\mathrm{IO}$ or another senior-level administrator. Law enforcement and emergency personnel should be provided with a copy of the plan for comment and integration into broader, areawide planning (Vogelweid 1998).

\section{REFERENCES}

AAALAC [Association for Assessment and Accreditation of Laboratory Animal Care] International. 2003. Who's responsible for offsite animals?

Connection Spring:6-11, 13. Available at www.aaalac.org/publications.

ACLAM [American College of Laboratory Animal Medicine]. 1996. Adequate Veterinary Care. Available at

www.aclam.org/education/guidelines/position adequatecare.html; accessed May 10, 2010.

Anderson LC. 2007. Institutional and IACUC responsibilities for animal care and use education and training programs. ILAR J 48:90-95.

AVMA [American Veterinary Medical Association]. 2008. Introduction to Ergonomics Guidelines for Veterinary Practice. April. Available at

www.avma.org/issues/policy/ergonomics.asp; accessed May 10, 2010.

AVMA. 2010. Programs accredited by the AVMA Committee on Veterinary Technician Education and Activities (CVTEA). Available at

www.avma.org/education/cvea/vettech programs/vettech programs.asp; accessed January 4, 2010.

Banks RE, Norton JN. 2008. A sample postapproval monitoring program in academia. ILAR J 49:402-418.

Bayne KA, Garnett NL. 2008. Mitigating risk, facilitating research. ILAR J 49:369-371. 